\title{
Problem Solving at Provinha Brazil: Implications of Educational Historical and Cultural Theory
}

\author{
José Carlos Miguel, V. P. Silva \\ Department of Didactics, Postgraduate Education Program, UNESP, Marilia, Brazil \\ Email: jocarmi@terra.com.br
}

Received 28 July 2015; accepted 8 September 2015; published 11 September 2015

Copyright (C) 2015 by authors and Scientific Research Publishing Inc.

This work is licensed under the Creative Commons Attribution International License (CC BY). http://creativecommons.org/licenses/by/4.0/

(c) (i) Open Access

\section{Abstract}

This study discusses the methodological perspective of problem solving facing the guidelines of the Reference Matrix Literacy Mathematics Home, Provinha Brazil, and their implications for teaching practice. Leaving ample literature, it proceeds to the documentary analysis of the latest attempts to curricular reorganization in the Brazilian context, with emphasis on categories established based on the themes traditionally broadcast in the classroom. The analysis is based on categories established from the great themes of mathematical science conveyed in the initial mathematical literacy and its implications for social, political and economic. Also it addresses aspects that stand out in discussions with teachers in initial or continuing education process. Results indicate distance between the ideas discussed in Provinha Brazil and the need to establish a satisfactory relationship which allows the meanings spectrum negotiations aimed at reworking of arithmetic procedures to make them more general, less dependent on contextual variables and less subject to errors of various kinds.

\section{Keywords}

Mathematical Literacy, Problem Solving, Concept Formation, Social Use, Provinha Brazil

\section{Introduction}

Troubleshooting can be characterized as a competence required for all people, whether in the context of everyday life, whether in the scientific context. In general, from the 1980s, all attempts to reform the teaching of mathematics programs maintain that the problem puts the subject to think, that is, to solve problems students develop reasoning skills and appropriates the necessary instrumental decision-making with autonomy of thought. 
D'ambrosio (1993: p. 9) states that the importance of mathematics education is firm in the school system, especially from the eighteenth century, with the advancement of modern science, technology development and industrial expansion. For the author, "the complexity of mathematics, especially for its relations with other areas of knowledge and its social, political and economic justification, since antiquity, reflections, theories and studies on their teaching."

Despite these findings about the intervention of socio cultural factors in the organization of educational programs, the fact is that the form of dissemination of mathematical knowledge in the Brazilian context still reflects a certain conception of the knowledge appropriation process. We can say that although the latest curricular reforms point to the mathematical knowledge of perspective as something under construction, there still prevails in everyday didactic action a conception of education according to which simply decompose knowledge into isolated fragments and then organize its dissemination to students in certain sequences. Strictly speaking, this pedagogical conduct in Mathematics is the same that guides the appropriation of mother tongue from the syllabication and then gets to the production of texts. In this way of thinking, the appropriation of mathematical fact is a linear motion and determined the parts to the whole, from the specific to the general.

No doubt, the discussion on the influence of socio-cultural contributions in the learning process led to the theory of didactics forward another way of understanding the question, establishing that knowledge is what is generally for what is private. To break away from those beliefs steeped in the dissemination of mathematical knowledge, it requires a number of basic and further training activities of educators as well as public policies aimed at renewal and evaluation of educational processes. In this sense, the systematic assessment which resulted in the proposal of Provinha Brazil makes sense. Agreeing with the importance of systematic assessment for the effectiveness of an educational action that worry about preparing people for citizenship, this study is the result of actions for the articulation between teaching, research and extension developed in the context of projects intervention in basic education of public.

\section{Objectives}

The study has the objective to discuss the meaning and principles of pedagogical action aimed at the formation of mathematical concepts and have the resolution of problems as major methodological guidelines. It considers that all knowledge results from a question and mathematics initiation is a key component of reading and writing processes.

Thus deals with the relationship between orality and writing in the constitutive movement of mathematics literacy, understanding that the appropriation of knowledge is a process that results from the search solving a problem. Lies also the analytical framework in the context of diagnostic evaluation of systematic concerns raised by Provinha Brazil that aims to investigate the development of skills related to literacy, comprising up mathematics as a language and an important instrument to support the reading process and writing. So,

Mathematical literacy is therefore the process of organizing experiences that the child brings their pre-school activities in order to get her to build a body of knowledge articulated that leverages its operations in citizen life. It is a long process that should later allow the subject to use mathematical ideas to understand the world in which he lives and instrumentalize it to solve challenging situations that will find in your life in society. It is necessary, therefore, to emphasize that the mathematical literacy means not only the domain of symbolic language. (Brazil, 2012: p. 23)

Therefore, the mathematical literacy may not appear as mere didactic action focused on the symbolic register of numerals or the mere recitation of numerical sequence. Even less for solving algorithmic procedures of which students have not always rule and that little use for his performance as participatory citizen, capable of decision making.

The problem that urges us can be translated into two main issues. There is consistency in the skills indicated in the formulation of Provinha Brazil? What reveal the classroom practices as the experiences focused on mathematical literacy?

Our hypothesis is that the formal systematization, premature and excessive, and the abuses of symbolic language, from the early stages of schooling, little or no contribution to the development of autonomous thinking. The imposing an educational process that considers children's experiences and allow create in class an incentive to curiosity environment and the discovery of the typical plan of social interactions. 


\section{Methods}

Leaving ample literature, proceeds to the document analysis on the curricular reorganization attempts in the post-1980 Brazilian context, with emphasis on the Reference Matrix content for Assessment of Mathematics Literacy Home, Provinha Brazil, and their implications for practice teaching. The analysis is based on categories established from the great themes of mathematical science conveyed in the initial mathematical literacy. Also addresses aspects that stand out in discussions with teachers in initial or continuing education process.

\subsection{Discussion and Results: Contributions to the Development of Mathematical Ideas}

The theoretical construct which is the mathematical thinking results, in general, responses to inquiries produced in different socio-cultural contexts and translated in the different forms of problem situations.

It consists of the implications substrate for the History of Mathematics in the complexity of its evolution and its revolutions. Corroborate, so many variations in its origins and in its context. At a certain historical moment, are problems arising from the human need to secure and organize their survival; now, the need to build a safe place to live, i.e. problems resulting from direct human action in nature and the social environment such as the division of land, credits, debts, etc. At other times are the problems posed by the interfaces with other sciences such as biology, physics, astronomy or chemistry without disregard situations and speculation inherent in the evolution of mathematics and the need to organize produced mathematical knowledge, and is structured in Function requirements of its distribution or form of teaching.

The fact is that problem solving is configured as central to the development of mathematical science process. It is the need to solve certain problems of human activity that has guided the development of mathematical ideas. However, the methodological treatment that has been given to the theme problem solving seems to consider such premises. The problems, in general, are presented to students in a decontextualized way, as mere imitative-repetitive application of operative techniques and algorithmic procedure. Nevertheless, for many authors problem solving is an instrument for the establishment of scientific thinking itself. Bachelard (1978), for example, believes that all knowledge is answer to a question; in short, to a problem.

Similarly, the National Curricular Parameters (1998: p. 52) we read that put in the context of problem solving

(...) Students acquire spirit of research, learning consulting, organizing data, systematize results, to validate solutions; develop their thinking skills, acquire self-confidence and sense of responsibility; and ultimately expand their autonomy and communication skills and argumentation.

It is possible to see the concern with this situation when the Reference Matrix for Evaluation of Literacy Mathematics Home, Provinha Brazil, indicates the powers it deems necessary for this step of literacy (Table 1)

Consolidate skills development as highlighted presupposes an educational action that must be guided by the proposition of situations that lead students to build relationships between the conceptual elements involved and to reflect on the ideas connected to this situation. This is to ensure a process in which the understanding of ideas

Table 1. Reference matrix for evaluation of literacy mathematics home, Provinha Brazil.

\begin{tabular}{ccc}
\hline $1^{\circ}$ Center Line & Numbers and Operations \\
\hline Competences & Descriptors/Skills \\
\hline
\end{tabular}

D1.1—Join the collections count objects to the numerical representation of their respective quantities.

C1-Mobilize ideas, concepts and structures related to the D1.2-Join the number of names to their respective symbolic represenconstruction of the meaning of numbers and their representa- tation.

D1.3-Compare or order quantity by counting to identify numerical equality or inequality.

D1.4-Compare and order natural numbers.

C2—Solve problems by adding or subtracting.

D2.1 - Solve problems that require actions to gather, sort, add and remove quantities.

D2.2-Solve problems that require actions to compare and supplement amounts.

C3-Solve problems through the application of the ideas that D3.1-Solve problems involving the ideas of multiplication. prepare for multiplication and division. 
and concepts is privileged to give the student the opportunity to develop their knowledge, establishing connections between math facts.

It is essential, then, that teachers can reflect on the nature of mathematical thinking and how it relates to the process of teaching and learning as well as on the role that mathematics language plays in this process. Therefore, the notion of number cannot be conveyed just as much idea, although in the initial process of mathematical literacy that is the dimension that shows more latent. Furthermore, we must drive the kids to realize that number may indicate a code as noted with the definitions of telephone lines, the zip code or the registration of the identity of persons. Or even that number may indicate order as notes in the denomination of popes or kings, or even the location of an apartment in a particular floor of a building.

Next in mathematical literacy process will require the post and before the above, the expansion of the number of idea to embrace notions on measures and the very need of explanation of new mathematical facts as the fractionation of a whole so present in society such as the notions of half, third or fourth part, for example. Are mathematical situations strictly social use which inappropriate development will not allow the consolidation of the processes of reading and writing become restricted and the social and cultural contributions of mathematical literacy.

With regard to ideas related to elementary mathematical operations it is necessary to highlight some points that still seem conflicting despite all the discussion of the issue in the last three decades. First, the educational work daily in kindergarten and early elementary school years could not fully guarantee that the proposed didactic situation should enable the child to solve problems, that is, from everyday situations, the teacher should aim opportunities put the child in front of a mathematical concept.

Although it is old pedagogical demand, initial and continuing training of educators still unable to establish for teachers of the set that the initial process of mathematical literacy cannot be mobilized from the preoccupation with the early development of formal systematization.

The classroom observation and interviews with literacy teachers indicate that many of them consider necessary to ensure primarily children access to the first letter and then think about the dissemination of mathematical ideas. But the fact is that many children come to school with well-developed mathematical notions, especially those involving the usual quantitative aspects of everyday life such as the use of money. Many know, for example, to form a real need for two coins of fifty cents or four coins twenty-five cents. It turns out that school to timidly consider premises of this nature in the organization of the pedagogical work, disregards mathematics and literacy component, i.e., relinquishes the support that mathematical notions must enable processes of reading and writing. Mother tongue language and mathematics seem disconnected this didactic stance.

In general, the prevailing concern of the development of algorithmic thinking teachers to subsequently apply it in problem solving. There is a historic reversal since the algorithms have been developed to solve specific mathematical situations and not vice versa. The pedagogical conduct these terms overlooking the fact that it is the action that determines the operation.

It is also fundamental to systematic exploration of ideas related to addition and subtraction as advocated in the Reference Matrix Provinha Brazil. The reviews of the use of them are still very difficult for children to solve problems of the type: "I have eight years. Lucas is 5 years. How old am I the most?" A significant number of children try to solve the problem by adding. It is interesting to note that if the question is "how much less" they resolve without difficulty. These are not just inattention or difficulties in semantic nature as some teachers. The problem has to do with the insufficient exploration of ideas to compare and complete, subtraction as merely addressing the notion of taking.

This cannot be solved only by the repetition of algorithmic procedures for subtraction, but requires reasoning formulation that leads the children understand the concept of subtraction as the action of finding the difference between two quantities. For us, this should be routed from the early childhood education process with mathematical situations involving amounts of comparison and the two-way matching idea or term by term:

Collection A

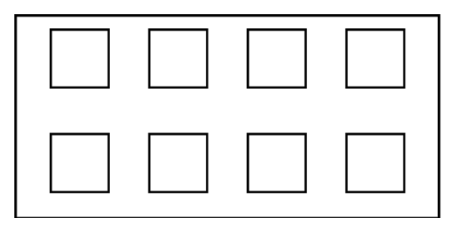

Collection B

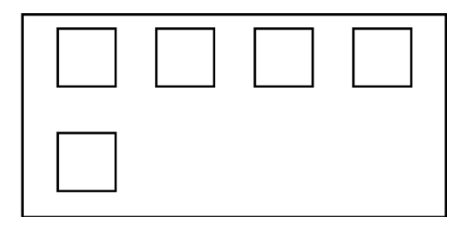


Such construction should begin manipulating concrete materials, preferably familiar objects or toys to children, to lead to the gradual formalization that stands on heuristics built by cognitive conflicts caused by developed pedagogical action.

Regarding the development of notions of multiplying, in short, the class observations indicate that basically explores the idea of multiplication as repeated addition of equal installments. The idea of this combinatorial reasoning on issues such as "how many different ways can dress taking 3 pants (blue, white and black) and 2 shirts (red and purple)" is rarely addressed. This could be conveyed including handling concrete material produced by children in cardboard.

Regarding the division, the concern with the construction of algorithms minimizes the pedagogical care that should exist with the exploitation of distribution one by one in the US this division process, which is developed naturally by this age group. Note the only the exploitation of equitable distribution, the idea also spread, rarely appearing problems involving the notion of measure, i.e. how many times a quantity fits into another.

Indeed, how the teacher conceives of Mathematics influences their way of understanding the process of teaching and learning of this discipline. If we see it as a developing science for humanity, from the problems that reality presents you, will be present concern to treat it that way with the students. Therefore, the school to disseminate mathematical content and encourage the development of organized and critical thinking contributes to the consolidation of the processes of reading and writing, to the perception of mathematics as a science and as cognitive instruments necessary for the understanding of the environment and by argument logical-deductive reasoning.

Contradictorily, reports of classroom situations in which students show skill in mental arithmetic are common, verbalize the reasoning to solve a problem, but show difficulties to record the actions taken. The limitations that have to explain heuristics put into practice and the difficulties of teachers to achieve the didactic transposition are known, that is, teachers perceive the distance between the mental, oral and written, but can not in practice turn Mathematics to teach it. For children, from an early age influenced by mathematics educated and with difficulty to express their misunderstandings, the dialogue is very limited. This virtually prevents the process of negotiation of meanings and learning meanings.

In our understanding, the analysis of these heuristics is essential to break with some practices that do not contribute to the development in students the ability to properly relate to information, knowledge and skills to solving mathematical situations. By this criterion, considerable portion of students completes primary school and is illiterate mathematically. In this discussion, it seems essential to consider that the formation of concepts is a complex action in which

the process cannot be reduced to the association, attention, training images, the inference, or to determine trends. All are necessary, but insufficient without the use of the sign, or the word as a means by which we conduct our mental operations, control its course and channeled towards solving a problem. (Vygotsky, 1999: pp. 72-73)

Certainly, the difficulties with the learning of mathematics are a synthesis of multiple determinations. Among them, the differences between mathematical knowledge experienced daily and educated math, uncertainties relating to political-pedagogical project of the school, negative spontaneous conceptions regarding mathematics and didactic or epistemological obstacles can lead students to a mathematical knowledge of context formalized, far from the ways of thinking and acting put into practice when they need immediate reality data logging, creating difficulties in assimilation of concepts.

From our point of view, it must be the formation of an epistemologically curious teacher, that is, able to see, interpret and consider the heuristics developed by students and who seeks the knowledge of theories plausible explanations for a consistent didactic and pedagogical action. This is the approach of the 2nd and 3rd axes involving the geometry notions and quantities and measures (Table 2).

The prospects outlined in the Curriculum Matrix for the placement of geometric ideas and quantities and measures are consistent. However, the conception of mathematics as something ready present in the teaching approach has hindered the satisfactory development of these skills in math literacy. You can also note that prevails an approach that evolves particular or specific aspect, the plane figures, for what is generally the spatial figures.

Regarding Quantities and Measurements theme, school practices still focus too much on standardized measures and consider some of the experiences brought by the children to school in respect of non-standard measures. 
In short, you can see that the problems of children in the evaluation result from broader issue is the precarious form of serving the mathematical notion of comparison, already widely discussed in the text. And basically measure is to compare, which allows us to infer that the school does not work properly with the formation of concepts.

\subsection{Data Processing: Tool for Problem Solving}

When we asked the teachers because students have many difficulties to solve problems in written form, though sometimes show competence to do so by use of mental calculation, they readily respond that the students do not know how to interpret the information contained in trouble. While this is partly true, the point is that teachers want this to be just a problem of the limitations of reading and writing processes. It is not; more than a difficulty inherent in the field of mother tongue, the problem relates to the form of diffusion of mathematical knowledge in the classroom, notably marked by repetitive processes.

In Reference Matrix for Evaluation of Literacy Mathematics Home that content have the analytical perspectives (Table 3).

Are absolutely relevant educational concerns, otherwise it will not consolidate the role of mathematics as literacy component. As we reflect on the importance of the statistical approach, as a language to be taught to develop the ability to read, interpret and organize mathematical data can not overlook the fact that in elementary school mathematics language should be at the service of solving concrete problems reality as a way to make sense of ownership of this process knowledge. We have then a first overview of the subject information processing approach in elementary school, that is, relating it to the troubleshooting process.

It is true that the resolution of problems has been established in central theme in the organization of educational programs educated Mathematics with emphasis in almost all curricular reforms implemented from the 1980s But it is also true that despite this, still prevails in the classroom an approach that basically consists in presenting some situations and indicate ways of solving using a specific surgical technique. Worse is that, since the problem by the teacher, is almost unison questioning the students about what operation leads to the solution.

Indeed, all assessment indicators point to the fact that impose students the simple manipulation of symbols with little meaning in the form of a set of mechanically memorized rules or repetitive algorithmic procedures, can contribute to establishing a general feeling front inability to everyday need to read, interpret and solve problems. Students reveal difficulty in interpreting the statements, cannot handle the information, hone her senses, establishing relations with the acquired knowledge, coordinating actions. If this difficulty is still present in significantly classroom, there is the need for change in the treatment of the contents, seeking new perspectives of

Table 2. Reference matrix for evaluation of literacy mathematics home, Provinha Brazil.

\begin{tabular}{|c|c|}
\hline $2^{\circ}$ Center Line & Geometry \\
\hline Competences & Descriptors/Skills \\
\hline \multirow{2}{*}{ C4—Recognize representations of geometric figures. } & D4.1-Identify flat geometric figures. \\
\hline & D4.2-Recognize representations of spatial geometric figures. \\
\hline $3^{\circ}$ Center Line & Quantities and Measures \\
\hline Competences & Descriptors/Skills \\
\hline \multirow{2}{*}{ C5-Identify, compare, relate and order quantities. } & D5.1-Compare and order lengths. \\
\hline & D5.2-Identify and relate notes and coins. \\
\hline C5-Identify, compare, relate and order quantities. & D5.3-Identify, compare, relate and order time in different measurement systems. \\
\hline
\end{tabular}

Table 3. Reference matrix for evaluation of literacy mathematics home, Provinha Brazil.

\begin{tabular}{ccc}
\hline \multicolumn{1}{c}{$\mathbf{4}^{\circ}$ Center Line } & & Data Processing \\
\hline \multicolumn{1}{c}{ Competences } & & Descriptors/Skills \\
\hline & D6.1-Identifying information presented in tables. \\
C6-Read and interpret data in graphs, & D6.2-Identifying information presented in column charts. \\
& D6.3-Identify information related to mathematics presented in different textual carriers. \\
\hline
\end{tabular}


working with this theme.

Basically there are three ways to approach to problem solving. In the first, teaching about problem solving, the teacher usually emphasizes the model of Polya or some adaptation hereunder. This model addresses, in short, a set of four interdependent phases: understanding the problem, developing a resolution plan, carry out this plan and look back the original problem by checking the compatibility of operations.

In the second approach, teach problem solving, the teacher gives priority to the way mathematics is widespread and that it can be used to solve problems conventional and unconventional. If the appropriation of mathematical knowledge is required, it is essential to know to use it. Therefore, teachers are dedicated to providing many concepts and mathematical structures on the content under study and strive to make possible situations in which this mathematical knowledge can be applied to solve problems. These two conceptions of education and mathematics, you learn by association models. The problem should be resolved as application of a concept or previously trained rule.

Under the influence of cognitive theories, from the 1980s, several attempts to curricular reorganization in the Brazilian context begin to question the teaching and the effect of strategies and models. Problem solving begins to be seen as a methodological perspective, that is, as a starting point and a way to teach math. In this third way of approaching the problem is conceived as triggering element of the knowledge construction process. From this perspective, the problem is the initial element of the mathematical concept of the training process and expresses central aspect of the situation addressed and should be developed mathematical ideas that may be appropriate responses to problems.

Contrary to the disenchantment of knowledge to be obtained routinely, the development of autonomy required to enable the student to solve problems by creative thinking, to deal with new situations with which you do not have much experience, but to establish relations with the previous knowledge. The issue lies at the core of the classic problem of transfer, to Bruner (1978): have seized something means to have developed the ability to, put an A situation, the student is able to move to a situation $B$, that is new but keep relationship with A. Unfortunately, most students at all levels of education, have difficulties to do so.

Certainly, research in mathematics education has already established that the contemporary trend is to characterize students as active subjects, problems as well defined instruments to trigger a training perspective concepts and activity, problem solving, as a complex simultaneous coordination of various levels of activity. The methodological perspective of problem solving aimed at a mathematics teaching approach that seeks the appropriation of knowledge with meaning. Consensus also seems the importance of coordination of the instrumental nature of mathematical knowledge, their practical and utilitarian aspects, with the dimension of intellectual development, which requires the ability to cope well with the information, abstracting, designing and generalizing.

The discussion on natural, scientific and social phenomena are worth, in general, the data gathering and analysis must be arranged in order to facilitate the socialization of certain information properly. Develop organizational skills, reading, presentation and analysis of data relating to a certain mathematical situation is a basic condition to solve it and to guide decision making about everyday events and phenomena.

Thus, it is undeniable that in the knowledge society, the sense that the world gets to people, comes from communication. More than just a "tightener" buttons, the world of relations of learning, working and production requires subjects endowed with decision-making capacity. Represent, speak, listen, read and produce texts are communication skills that should be part of mathematics learning. Therefore, in order to develop the capacity to organize and represent the data available from a given mathematical situation, students need to know how to read, interpret and draw conclusions from tables, charts and graphs. This is a fundamental condition for the consolidation of the processes of reading and writing, which should occur throughout elementary school.

Strictly speaking, it is truly literate the guy who is able to read and interpret numerical data presented in an organized manner. But consider, too, that this capacity is not developed only by contemplation. From our point of view, it is essential that an initial work with the theme put the students in search of some recent research in newspapers, magazines or on the internet, bring the data to the classroom in the form of tables, graphs or diagrams and to develop and solve problems with the data. The media use this quotidian language is indispensable decode such forms of visual representation. Therefore, a mathematics teaching proposal situated in the perspective of concept formation cannot do without developing the capacity to collect data and organize information available.

How to register the monthly data consumption of piped water from four students in the class residences in the first half of the year? You can start work asking students to take water bills for the classroom. At first it is possible 
for them to do based schemes relate the names and register, month by month, consumption. Following fulfills help them organize the data on the form of tables or graphics. Questioning students about the causes of the increase in consumption as well as on the relationship between consumption and account cost can result in interesting discussions and that go beyond the mere limit the collection and organization of data. These activities may be mediated by a scribe or draftsman, chosen in the class, or even the teacher himself, due to students not yet have much aplomb with writing.

It is possible that they respond that people consume in excess in the months of intense summer or reducing consumption by the seasonal effect of the fall or winter approaches. Or the effect of a campaign for rational use of water. If these reasons do not appear, it is the intervention of the teacher who seeks an interdisciplinary treatment program content. This is a topic always interesting because of economic, political, social, ecological and environmental involved.

To questions about the possible cause for the sharp reduction of water consumption in a month in a residence when all other households had consumption close to the previous month, we expect them to respond that the family may have traveled on vacation or that month has been engaged for reduction, which was abandoned in some way in subsequent months. All this is relevant, but it is also important that they can organize these data in tables or graphs that put this procedure facilitates the reading and interpretation. Also, it lets you explore problem solving with core operations from data and concrete situations.

A promising action is to relate cost and consumption of piped water and discuss with students the reasons and consequences of this procedure that is adopted by some governments, that is, the cost of cubic meters of water increases as you advance in levels of consumption. It reveals how beneficial this case lead students to conclude that it should have the impact of reducing consumption conscious, but not usually because people did not even pay attention to the fact. Although it is a communication problem, it is also a matter of citizenship both in the ecological aspect and the economic.

Allowing exploration of problems on all elementary mathematical operations, this procedure may be extended in subsequent studies to complex mathematical topics such as the 1st degree functions at intervals of water consumption. It will also enable give meaning to content which usually appear in a decontextualized way in the curriculum, such as theme Expressions Numeric. Or the relationship between liter and cubic meter. These procedures are important because they reveal students mathematics as a building process. In didactically appropriate time, preparation of charts and graphs as well as explorations of the medium of concepts, arithmetic and weighted, as appropriate, complement the senses production process and negotiation of meanings in mathematics learning. And improve the record of the situation produced initially.

Having four shirts (white, red, pink, yellow) and three pants (black, blue and brown), how many different ways I can get dressed? Students can try to solve this problem by adopting schemes, although they may forget some combination. But it is a way to empirically develop the notion of Cartesian product and multiplication as combinatorial reasoning generally forgotten in elementary school. Applying this scheme, they may conclude that there are 12 different ways to wear. However, it is necessary to encourage them to develop other forms of symbolic register to facilitate communication both as problem solving. They can take advantage of the strategy of setting one of the pieces (white shirt) and relate to each pant color. Finally, they can take advantage of a twoway table.

In either used schemes is essential to the conduct of students to the conclusion that there are $4 \times 3=12$ different ways of dressing. And realize the regularities that are established in the constitution of ordered pairs. Other possibilities for exploitation of combinatorial reasoning are snacks compositions with soft drinks, ice cream with toppings, hot with cold, etc.

This teaching posture to explore different forms or given information addressing schemes, or to solve a problem, find support in the theoretical perspective DUVAL (2003). For this author, you can only understand or grasp the mathematics from the use of semiotic representations of mathematical object, i.e., the student must mobilize such representations to truly know. This requires the instantaneous conversion of a mathematical object in another semiotic representation of another system, which is most significant from a cognitive point of view, to the effective resolution of a given problem. Called the semiotic function to the ability of an individual has to produce mental images of objects or actions and make their representations.

Strictly speaking, it is the semiotic function that allows the thought, a fact that also finds support in Vygotsky, since for this author the development of mental representations is associated with the internalization of semiotic representations initiated by the mother tongue. DUVAL ensures that one should not confuse an object with its 
representation. Thus, the drawing of a circle, the circumference word itself or the equation of the circumference which are different representations refer to the conceptual object circumference, but none of them is actually the circumference, only represent. Nevertheless, they are records that allow access to the object and treatment of the object.

It also establishes that the understanding of the information or the mathematical activity lies in the simultaneous mobilization of at least two registers of representation, or the possibility to change at any time representation of record. Coordination of at least two registers of representation manifests the speed and spontaneity of cognitive activity of conversion. This allows us to move in reflection. Why do people do research? It is necessary to consult everyone for a good predictability of the result of research? If the owner of an ice cream shop needs to have a rough idea about the preference of ice cream consumption in a given neighborhood, for example, to organize the inventory, it must consult all the people in the neighborhood?

From our point of view, a theme approach Treatment Information cannot do without engaging students in discussions of this nature. Likewise it is impractical for a research institute consults all voters to make a preview of the outcome of the election, so the ice cream does not need to consult all consumers to have a good size of the preference of their customers. The procedure in such cases is to get the data from a sample of voters or consumers to draw conclusions with good approximation for the entire group studied. The Statistics understood as a method for study collective behavior, allows conclusions translated into numerical results with good accuracy.

The approach of this issue in mathematics literacy requires not engage students in a very thorough job with the fundamentals of descriptive statistics, of course. But imposes lead them to data collection actions on certain situations, analyzing the behavior of a variable, condensing the data in the form of tables or graphs, interpreting them and solving problems with a view to developing the notion of how to make a search. In the example on the consumer preference for ice cream, a simple questionnaire may constitute a good tool to explore this idea with students and engage them in a process of organizing for data communication and for the development of resolution process problems from a concrete situation. The questionnaire can be applied with the students of the class.

Problem solving should lead students to interpret the data, establishing relationships by applying mathematical concepts related to numbers, to space exploration and shapes, the quantities and measures and statistics, interesting procedures for negotiating meanings and production theme learning senses Treatment Information. However, it is also important to realize the fact that sometimes these results are approaches that rely heavily on the sample profile. This is a key theme for the contextualization of mathematical facts, contributing to the development of an active process of establishment of relations between ideas and coordination of actions.

So it is critical to engage students in educational situations that might lead them to realize that hotels do surveys on the satisfaction of service to its customers; political parties are among its previous members to indicate the candidates most likely to win an election; companies do research among consumers to define whether their products have market acceptance; education systems develop research on the performance of schools; or that the housing policy of a municipality can be defined based on the indicators of population growth, particularly in the reasons for this growth in a given period. All this can be explored including dramatizations of students and contributes to the perception of mathematics as a building process.

\subsection{Pedagogical Implications and Intervention Perspectives on School Reality}

An accurate analysis of the Reference Array must point to the fact that the reflection of educators on oral manifestations of mental action developed to solve problems plays a fundamental role in the mathematical representation in written form. Hence the importance of a pedagogical action progressively forwarded to the difficulties in understanding the statement, encouraging solution strategies developed from the interaction and exchange of ideas among the subjects on the results obtained.

Hence, the need to analyze the texts of the students, speech, oral histories, finally, the heuristics that develop to learn and that could support the process of preparation by students in math literacy. So it is important educator awareness with regard to educational objectives proposed to use mathematical language in order to achieve the proposed goals for literacy. That is, Mathematical plays a key role in supporting the reading and writing process; it is a component of the extensive process of literacy. It is understood that the formation of the human being is the result of social interactions and, as appropriates the knowledge, modifies its socio-cultural context to the degree which is modified by this context.

Lorenzato considers that the child enters school with a relatively wide range of knowledge stemming from 
their social context that should be explored and suggests to start the development of basic concepts "where children are and not where we would like them to be” (Lorenzato, 2005: p. 24), becoming thus an exploration of knowledge already built by the students and relating them to the concepts and notions of space, number and measures to guide the teaching plan.

Exploitation of this language, that students bring to the classroom, part of the basis for the concept of training because they already know the meaning, just look empirically illustrate to form the basic concept of mathematics to the information provided. In short, give meaning to learning.

Sometimes schools have good collection of resources for the development of this exploratory work. However, it is necessary availability of the educator to carry out activities in the classroom, making room for dialogue, discussions and conceptual records.

This dialogical learning process requires, according Nacarato, Mengali \& Steps a “[...] environment to voice and hear students analyze what they have to say and establish communication based on respect and (with) sharing of ideas and knowledge "(Nacarato, Mengali, \& Passos, 2009: p 42), providing a positive environment for the appropriation of knowledge by students.

\subsection{On the Dialectical Relationship between the Oral and Written Mathematics Learning}

Bakhtin (1986: p. 92) considers that the speaker makes use of the language to their specific needs enunciation, that is, to the language of the speaker construction is oriented towards enunciation of speech, that is, we need the speech to the exercise of language and language, to the existence of social interaction. On the basis of this thinking, dialogism is the constitutive principle of language, that is, interacting through language subjects organize and systematize their knowledge so that all cognitive activity to reach maturity is expressed through language (written or spoken). That is, the activity of knowing is also determined by the outside world.

The historical-cultural theory has already established that the sign mediates not only thought, but the very human social process. This includes, among the signs, language, counting systems, schemes, diagrams, maps, drawings, algebraic symbolic systems, mnemonic techniques and all sorts of conventional signs. The basic idea is that by employing them, man modifies its own higher mental functions.

It is considered that the activity of which thought emerges is always heterogeneous, implying that thought is always heterogeneous, regardless of culture or time, a fact long recognized in so-called sciences of culture, but that has not been considered, as should the search. Consider that an activity involves, engenders or determine a specific type of thinking means taking a developmental approach and investigate the mediational potential of oral or written language as a tool, or explain how symbolic systems lend themselves to interact with systems already developed and what are the roles played.

Distinguishing between spontaneous concepts (developed by contact with facts and situations of their daily action, of which the subject has sometimes consciousness) and scientific concepts (systematized and transmitted intentionally, in general, in the school situation), the Vygotsky's investigations and colleagues attribute decisive role in the teacher's action, or more experienced partner, considering that learning through demonstrations assumes reconstitution of a given social model, not by pure and simple imitation, but an action that presupposes a constructive trial imposing changes to the model, in the process resulting in internalization of their understanding.

It seems consensus that the social space of the classroom should be configured as a condition for the production of knowledge. Thus, the main objective of mathematical activity is to lead the individual to transcend what is immediately responsive. In a sense, orality allows express and interpret what we see, hear or read of roughly or need. In another, the mathematical reasoning links up support in their own language in its syntactic organization and in its deductive power.

The establishment of a dialogical relationship in mathematical literacy should start from the assumption that not just the mechanical reproduction of school procedures nor the patience to explain again if we use the same teaching resources and scientific arguments. It is essential that students are involved in a process of redefinition of the concepts, establishing connections between the meaning and the meaning of mathematical concepts, have dominion over them and can relate them to those who along with his colleagues use in non-school activities.

Making Mathematics imposes thinking about how to design a scenario in which the essential features of labor discipline are respected, taking into account students' knowledge. This implies that a mathematical knowledge production process is developed with the knowledge and tools that are available, that is, one has to consider the notion of provisional conception of knowledge we hold. 
In this sense, orality and dialogy perform the important role of facilitating the understanding of these heuristics by the educator, and the very meaning of the problem forward the development of an informal strategy, next to the design that the student has the mathematical situation, but As regards the basic properties of the mathematical model in question. The constant approach dialogued situations could eventually lead to the spread of a procedure, making surgical technique of logic something more transparent to the student.

It is generally considered that the previous knowledge has limited range and that "mistakes" have role to play in the creation of new knowledge. This particular way of knowing, this "prior knowledge” almost always successful in a specific area of action, but others do not, is the source of the errors that allow the manifestation of obstacles.

This possibility is realized only within the limits of a dialogue-based action it considers the relationship between oral and written in mathematical learning and that would enable even the initial trial by surveying and testing hypotheses in a trial and error scheme for, subsequently, develop algebraic model as a generalization. For exceeding the symbolism and attempting to early development of algorithmic thinking lose up excellent opportunities for encouraging creativity, thinking autonomous, while playing with mathematics, in short, the full development of logical-abstract reasoning prevents so-hyped us teaching plans, in addition to losing a key dimension of mathematical thinking that is its playful aspect, playing with the mathematical relationships.

In fact, students sometimes even appropriate the mathematical situation, but even those who can solve it with some competence do not understand its meaning, transferring this knowledge to practical situations of problem solving.

\section{Conclusion}

Involving a student in mathematical literacy process guided by the perspective of problem solving is not just to do so by storing results in mind by repetitive, predictable and trained procedures. More than that, it means preparing you to participate in the process that enables the establishment of knowledge. In turn, it is the dialogical relationship that allows the meanings spectrum negotiations aimed at reworking of arithmetic procedures to make them more general, less dependent on contextual variables and less prone to errors of various kinds.

Be clear that the student develops logical reasoning participating in activities, acting and reflecting on the reality that surrounds them, actively using the information available to it constitutes an important step in that direction. In this sense, literacy must be based on mathematical situations able to enable active participation in the development of mathematical knowledge. It is the appreciation of the students' elaborations that teacher can better understand how it develops the reasoning of the student, which can facilitate the preparation of lessons and the proposition consistent activities to their intellectual development.

When treated separately in the curriculum, the mathematical facts are not fully understood, nor are incorporated by students as appropriate tools for solving everyday problems and the formation of other concepts of social use, useful for improving the intellectual training. The connections that the students manage to establish between the different themes of mathematics, those with other areas of knowledge and the everyday situations are what will determine the meaning of mathematical activity.

Then, the mathematical educator must make sure that mathematics literacy is a social activity whose objectification should include the interaction between subjects in various forms of communication and expression, that is, respecting the different logics and ways of thinking.

\section{References}

Bachelard, G. (1978). The Scientific Spirit. São Paulo: Martins Fontes.

Bakhtin, M. (1986). Marxism and Philosophy of Language. São Paulo: Hucitec.

Brazil, Ministry of Education and Sport. National Institute of Educational Studies AnísioTeixeira. (INEP) (2012). Item Preparation Guide: Provinha Brazil (p. 23). Brasília-DF: INEP.

Bruner, J. S. (1978). The Education Process. São Paulo: Nacional.

D’ambrosio, U. (1993). Mathematics Education: A View of the State of the Art. Pro-Posições, 4, mar.. Unicamp, Campinas, SP. Lorenzato, S. (2005). Early Childhood Education and Mathematics Perception. Campinas: Autores Associados.

Nacarato, A. M., Mengali, B. L. S., \& Passos, C. B. (2009). The Mathematics in the Early Grades of Elementary School: Weaving the Threads of Learning. Belo Horizonte: Autêntica.

Vygotsky, L. S. (1999). Thought and Language. São Paulo: Martins Fontes. 